\title{
A Standardized Inoculation Protocol to Test Wheat Cultivars for Reaction to Head Blast Caused by Magnaporthe oryzae (Triticum pathotype)
}

\begin{abstract}
C. D. Cruz, W. W. Bockus, J. P. Stack, and B. Valent, Department of Plant Pathology, Kansas State University, Manhattan, KS 66506; J. N. Maciel, Embrapa Wheat, Brazilian Agricultural Research Corporation, Brazil; and G. L. Peterson, USDA-ARS, Foreign Disease-Weed Science Research Unit, Fort Detrick, MD 21702
\end{abstract}

Accepted for publication 12 August 2016.

Wheat blast, caused by the Triticum pathotype of Magnaporthe oryzae (MoT), poses a significant threat to wheat production worldwide. Because this pathotype does not occur in the United States, it is important to prepare for its possible introduction. As part of this preparation, over 500 U.S. wheat cultivars were tested for susceptibility or resistance to head blast (Cruz et al. 2012; Cruz et al. 2016). Inoculations were conducted under biosafetylevel 3 conditions at Ft. Detrick, MD, and Kansas State University, Manhattan, KS. However, the protocols to phenotype wheat cultivars vary among researchers (Cruz et al. 2012; Cruz et al. 2016; Maciel et al. 2014). Therefore, in light of the recent outbreak in Bangladesh and the threat to wheat production globally, head blast inoculation protocols need to be standardized so that results can be easily interpreted and shared internationally.

The following protocol, based on several years' experience, is recommended for common use to facilitate direct comparison of disease phenotyping results among researchers. Researchers should grow plants under recommended local fertilizer/environmental conditions in a greenhouse or growth chamber until the late boot stage (Feekes 10). Inoculum should be prepared with spores from $\leq 7$-day-old MoT cultures grown at about $25^{\circ} \mathrm{C}$ on oat meal agar (heat $50 \mathrm{~g}$ of rolled oats in $500 \mathrm{ml}$ water at $70^{\circ} \mathrm{C}$ for 1 $\mathrm{h}$, squeeze through four layers of cheesecloth, adjust to 1 liter with water, add $15 \mathrm{~g}$ agar and autoclave) (Valent et al. 1991). Spores significantly older than 7 days begin to loose infectivity. Although several types of atomizers are effective, an airbrush similar to those that accurately apply paint is recommended (Harbor Freight Tools, Camarillo, CA) (Fig. 1). Within two days of full head emergence from the boot, each head is inoculated with $0.75 \mathrm{ml}$ of a conidial suspension of MoT $(20,000$ spores $/ \mathrm{ml}$ in sterile deionized water with $0.42 \%$ unflavored gelatine and $0.01 \%$ Tween 20). A minimum of 10 heads are inoculated per cultivar-isolate combination and those that show potential resistance are re-tested. To induce infection, inoculated heads are immediately enclosed in $7.4-\times 12.4-\mathrm{cm}$ plastic bags with a zipper closure (Uline, Pleasant Prairie, WI) that are moistened on the inside with water from a spray bottle (Fig. 1). Bags are removed $48 \mathrm{~h}$ after inoculation. Post inoculation, plants are cultivated at $28 \pm 2{ }^{\circ} \mathrm{C}$ (14-h day) and $23 \pm 2{ }^{\circ} \mathrm{C}(10$-h night) with at least 150 $\mu \mathrm{mol} / \mathrm{m} / \mathrm{s}$ light intensity. Each head is rated 10 to 14 days postinoculation for percentage killed spikelets (Fig. 2), referred to as

Corresponding author: W. W. Bockus. Email: bockus@ksu.edu.

doi:10.1094/PHP-BR-16-0041

(C) 2016 The American Phytopathological Society the head blast index. Disease ratings are done when the susceptible check cultivar reaches 90 to $100 \%$.

Differences in assessing the rate and amount of disease can occur among researchers, even when using essentially the same protocol. To minimize variance in the head blast index among researchers, inoculated wheat heads should be rated when the head blast index on the susceptible check just reaches 90 to $100 \%$. Rating cultivars after the susceptible check reaches $100 \%$ may mask potentially useful moderately resistant cultivars because disease may continue to develop on these cultivars over time. In conclusion, investigators using artificial methods to phenotype wheat cultivars for reaction to head blast are encouraged to use this protocol to facilitate worldwide communication of data on the reaction of wheat cultivars to this devastating disease.

\section{ACKNOWLEDGMENTS}

The project has been funded by Agriculture and Food Research Initiative Competitive Grants no. 2009-55605-05201 and 2013-6800420378 from the USDA National Institute of Food and Agriculture. Contribution no. 17-047-J from the Kansas Agricultural Experiment Station. Mention of trade names or commercial products in this publication is solely for the purpose of providing specific information and does not imply recommendation or endorsement by the USDA. USDA is an equal opportunity provider and employer.

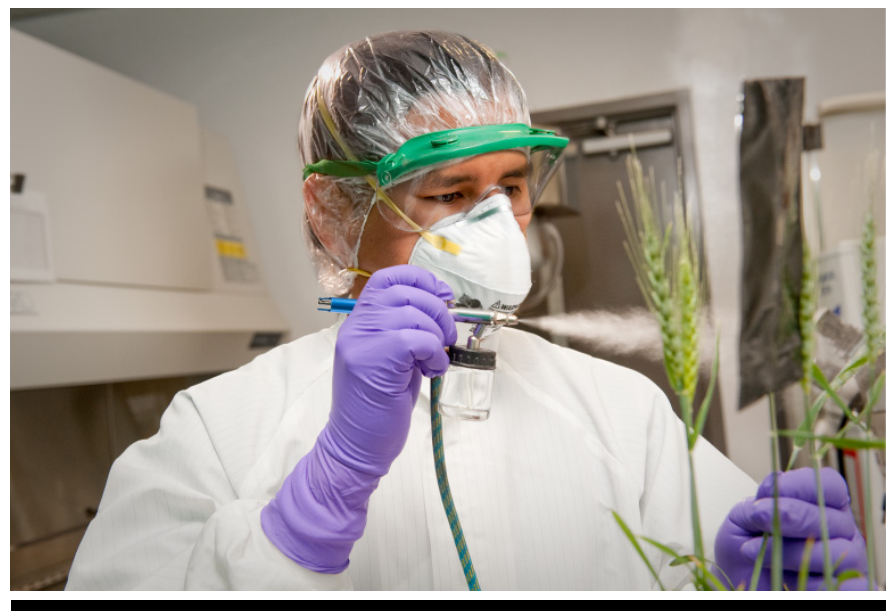

FIGURE 1

Inoculation of wheat head using an airbrush and showing an inoculated, bagged head (courtesy Kansas State University Photo Services). 


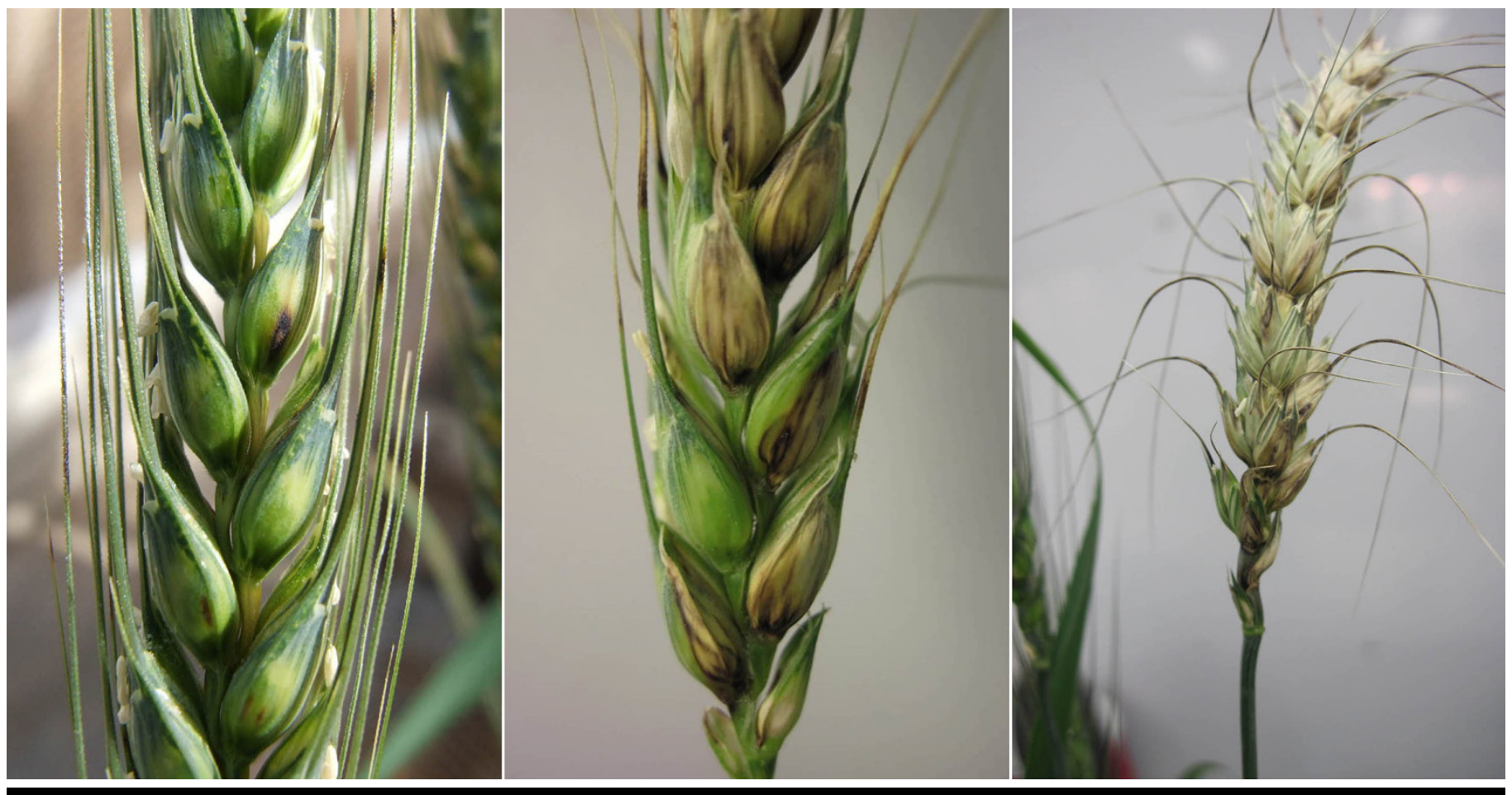

FIGURE 2

Development of wheat head blast on artificially-inoculated heads: early symptoms (left), expansion of early symptoms (center), and death of head (right).

\section{LITERATURE CITED}

Cruz, C. D., Bockus, W. W., Stack, J. P., Tang, X., Valent, B., Pedley, K. F., and Peterson, G. L. 2012. Preliminary assessment of resistance among U.S. wheat cultivars to the Triticum pathotype of Magnaporthe oryzae. Plant Dis. 96:1501-1505.

Cruz, C. D., Peterson, G. L., Bockus, W. W., Kankanala, P., Dubcovsky, J., Jordan, K. W., Akhunov, E., Chumley, F. G., Baldelomar, D. F., and
Valent, B. 2016. The 2NS translocation from Aegilops ventricosa confers resistance to the Triticum pathotype of Magnaporthe oryzae. Crop Sci. $56: 1-11$.

Maciel, J. L. N., Ceresini, P. C., Castroagudin, V. L., Zala, M., Kema, G. H. J., and McDonald, B. A. 2014. Population structure and pathotype diversity of the wheat blast pathogen Magnaporthe oryzae 25 years after its emergence in Brazil. Phytopathology 104:95-107.

Valent, B., Farrall, L., and Chumley, F. G. 1991. Magnaporthe grisea genes for pathogenicity and virulence identified through a series of backcrosses. Genetics 127:87-101. 